June $2000 \quad$ • NREL/CP-500-27891

\title{
Wind-Tunnel Tests of Two Airfoils for Wind Turbines Operating at High Reynolds Numbers
}

Dan M. Sommers

Airfoils Incorporated

James L. Tangler

National Renewable Energy Laboratory

Presented at the ASME Wind Energy Symposium Reno, Nevada

January 10-13, 2000

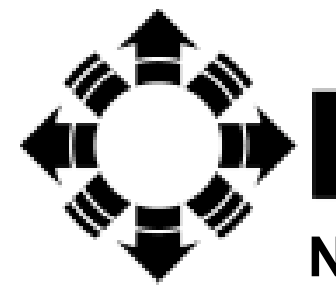

\section{NPEI}

National Renewable Energy Laboratory

1617 Cole Boulevard

Golden, Colorado 80401-3393

NREL is a U.S. Department of Energy Laboratory

Operated by Midwest Research Institute $\bullet$ Battelle $\bullet$ Bechtel

Contract No. DE-AC36-99-G010337 


\section{NOTICE}

The submitted manuscript has been offered by an employee of the Midwest Research Institute (MRI), a contractor of the US Government under Contract No. DE-AC36-99G010337. Accordingly, the US Government and MRI retain a nonexclusive royalty-free license to publish or reproduce the published form of this contribution, or allow others to do so, for US Government purposes.

This report was prepared as an account of work sponsored by an agency of the United States government. Neither the United States government nor any agency thereof, nor any of their employees, makes any warranty, express or implied, or assumes any legal liability or responsibility for the accuracy, completeness, or usefulness of any information, apparatus, product, or process disclosed, or represents that its use would not infringe privately owned rights. Reference herein to any specific commercial product, process, or service by trade name, trademark, manufacturer, or otherwise does not necessarily constitute or imply its endorsement, recommendation, or favoring by the United States government or any agency thereof. The views and opinions of authors expressed herein do not necessarily state or reflect those of the United States government or any agency thereof.

Available electronically at http://www.doe.gov/bridge

Available for a processing fee to U.S. Department of Energy and its contractors, in paper, from:

U.S. Department of Energy

Office of Scientific and Technical Information

P.O. Box 62

Oak Ridge, TN 37831-0062

phone: 865.576 .8401

fax: 865.576.5728

email: reports@adonis.osti.gov

Available for sale to the public, in paper, from:

U.S. Department of Commerce

National Technical Information Service

5285 Port Royal Road

Springfield, VA 22161

phone: 800.553 .6847

fax: 703.605.6900

email: orders@ntis.fedworld.gov

online ordering: http://www.ntis.gov/ordering.htm

Printed on paper containing at least $50 \%$ wastepaper, including $20 \%$ postconsumer waste 


\section{Wind-Tunnel Tests of Two Airfoils for Wind Turbines Operating at High Reynolds Numbers}

\author{
Dan M. Somers \\ Airfoils Incorporated \\ 122 Rose Drive \\ Port Matilda, Pennsylvania 16870-9483
}

\author{
James L. Tangler \\ National Renewable Energy Laboratory \\ 1617 Cole Boulevard \\ Golden, Colorado, 80401-3393
}

\begin{abstract}
The objectives of this study were to verify the predictions of the Eppler Airfoil Design and Analysis Code for Reynolds numbers up to $6 \times 10^{6}$ and to acquire the section characteristics of two airfoils being considered for large, megawatt-size wind turbines. One airfoil, the S825, was designed to achieve a high maximum lift coefficient suitable for variable-speed machines. The other airfoil, the S827, was designed to achieve a low maximum lift coefficient suitable for stall-regulated machines. Both airfoils were tested in the NASA Langley Low-Turbulence Pressure Tunnel (LTPT) for smooth, fixed-transition, and rough surface conditions at Reynolds numbers of $1,2,3,4$, and $6 \times$ $10^{6}$. The results show the maximum lift coefficient of both airfoils is substantially underpredicted for Reynolds numbers over $3 \times 10^{6}$ and emphasized the difficulty of designing low-lift airfoils for high Reynolds numbers.

\section{Symbols}

$\mathrm{C}_{\mathrm{p}} \quad$ pressure coefficient

c airfoil chord

$\mathrm{c}_{\mathrm{d}} \quad$ section profile drag

$\mathrm{c}_{l} \quad$ section lift coefficient

$\mathrm{c}_{\mathrm{m}} \quad$ section moment coefficient

L. lower surface

R Reynolds number

S. boundary-layer separation point

T. boundary-layer transition location

U. upper surface

$\mathrm{x} \quad$ airfoil abscissa

$\alpha \quad$ angle of attack relative to airfoil chord Subcripts

$11 \quad$ lower limit of low-drag range

$\max \quad$ maximum

min minimum

ul upper limit of low-drag range
\end{abstract}

This material is declared a work of the U.S. Government and is not subject to copyright protection in the United States.

\section{Introduction}

Verification of codes used for the design of windturbine airfoils, such as the Eppler Airfoil Design and Analysis Code ${ }^{1}$, has been limited to Reynolds numbers below $3 \times 10^{6}$ by the unavailability of high-Reynoldsnumber, wind-tunnel facilities. With the recent trend toward larger turbines, rated at over one megawatt, the currently available airfoil data are inadequate for the purpose of designing or predicting rotor performance. In addition, high-Reynolds-number, airfoil-code verification is needed for the prediction of both the maximum lift coefficient $\left(\mathrm{c}_{l, \max }\right)$ and the width and depth of the low-drag range.

The NASA Langley Low-Turbulence Pressure Tunnel $(\text { LTPT })^{2,3}$ was used for this study because it is the only two-dimensional wind tunnel capable of chord Reynolds numbers greater than $4 \times 10^{6}$ with low turbulence $(\leq 0.05 \%)$. Two airfoils, the S825 and S827, from the National Renewable Energy Laboratory (NREL) airfoil families ${ }^{4}$ were tested. Each airfoil was tested for smooth, fixed transition, and rough surface conditions at Reynolds number of $1,2,3,4$, and $6 \times$ $10^{6}$.

This paper is condensed from the two reports, which includes the airfoil coordinates, covering this study.

\section{Airfoils}

The 17-percent thick S825 airfoil was designed to achieve a high maximum lift coefficient $(\geq 1.40)$ suitable for variable-speed wind turbines. The 21percent thick S827 airfoil was designed to achieve a

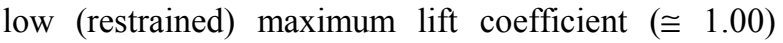
suitable for large, stall-regulated machines. Both airfoils were designed to achieve extensive laminar flow ( $\geq 30$-percent chord) on both the upper and lower surfaces for low drag. Transition to turbulent flow moves to the leading edge just prior to reaching maximum lift, which minimizes the effect of roughness on the maximum lift coefficient. Both airfoils were designed to exhibit benign laminar separation bubbles near the leading edge at maximum lift coefficient. More severe bubbles can lead to unpredictable and erratic 
maximum-lift-coefficient behavior. The design specifications for the two airfoils are shown in Table 1 and the airfoil shapes are shown in Fig. 1.

\section{Experimental Procedure}

Wind Tunnel

The NASA Langley Low-Turbulence Pressure Tunnel (LTPT) is a closed-throat, single-return tunnel (Fig. 2) that can be operated at stagnation pressures from 100 to $1000 \mathrm{kPa}$ (1 to $10 \mathrm{~atm})$. The unit Reynolds number can be varied from $1 \times 10^{6}$ to $49 \times 10^{6}$ per meter $\left(0.3 \times 10^{6}\right.$ to $15 \times 10^{6}$ per foot); the Mach number can be varied from 0.05 to 0.47 . The turbulence level in the test section $^{7}$ is generally below 0.05 percent for unit Reynolds number up to $13 \times 10^{6}$ per meter $\left(4 \times 10^{6}\right.$ per foot) at Mach numbers up to 0.15 .

The wind tunnel test section is $91 \mathrm{~cm}$ (36 in.) wide by $229 \mathrm{~cm}$ (90 in.) high. Hydraulically actuated circular plates provide positioning and attachment for the twodimensional model (Fig. 3). The plates are flush with the tunnel sidewalls and rotate with the model. The axis of rotation coincided approximately with the midchord of the model, which was mounted horizontally between the plates. The gaps between the model and the plates were sealed.

\section{Models}

Advanced Technologies, Incorporated, Newport News, Virginia fabricated the two wind-tunnel models from solid aluminum using a numerically controlled milling machine. The models had a chord of $457 \mathrm{~mm}$ (18.0 in.) and a span of $91 \mathrm{~cm}$ (36.0 in.). The measured model contours were within $0.1 \mathrm{~mm}(0.005$ in.) of the prescribed shapes.

Each model included a total of 120 chordwise pressure ports over the upper and lower surface. Upper- and lower-surface orifices were located to one side of midspan, staggered along a line approximately 10 degrees from the free steam flow direction. All the orifices were $0.51 \mathrm{~mm}(0.020 \mathrm{in}$.) in diameter with their axes perpendicular to the airfoil surface.

\section{Instrumentation}

Measurements of the pressures on the model and in the wake were made by an electronically scanned, pressure-transducer system. Basic tunnel pressures were measured with precision quartz manometers. Data were recorded by an electronic data-acquisition system.
Methods

The measured pressure distributions were integrated to determine the lift coefficients. Profile drag was measured using a total- and static-pressure, wakesurvey probe. The probe was positioned spanwise at the tunnel centerline. The tip of the probe was located 1.84 chord downstream of the trailing-edge of the model and could traverse the entire wake profile.

Standard, low-speed, wind-tunnel boundary corrections ${ }^{8}$ have been applied to the data, along with the wake-survey-probe total-pressure-tube displacement correction?

Tests

The models were tested at Reynolds numbers, based on airfoil chord, of 1, 2, 3, 4, and $6 \times 10^{6}$ and a Mach number of 0.1 with transition free (smooth), with transition fixed, and with a grit roughness scaled from NACA standard roughness ${ }^{10}$. Transition was fixed using grit roughness that decreased in size with increasing Reynolds number. ${ }^{11}$ as seen in Table 2 . The grit was located at 2-percent chord on the upper surface and 5-percent chord on the lower surface. It was sparsely distributed along $3-\mathrm{mm}(0.1-$ in.) wide strips applied to the model with lacquer. The scaled, NACA standard roughness consisted of $0.211-\mathrm{mm}(0.0083$-in.) grit applied from 8-percent-chord arc length on the upper surface to 8-percent-chord arc length on the lower surface for all Reynolds numbers. The grit size was scaled from the NACA standard-roughness grit size by the ratio of the model chord used in the present investigation to the model chord used in the NACA tests.

\section{Results}

Pressure Distributions

Typical measured pressure distributions for the S825 and S827 airfoils are shown in Fig. 4 for an angle of attack of 3.0 degrees. The integrated pressure distributions then yielded $\mathrm{c}_{l}$ versus angle of attack plots, which were documented for the complete test matrix.

Section Characteristics of S825 Airfoil

The theoretical and experimental section characteristics of the S825 airfoil for the design Reynolds number of 2 $\times 10^{6}$ are shown in Fig. 5. The measured maximum lift coefficient is 1.56 , which satisfies the design objective of $\mathrm{c}_{l, \text { max }} \geq 1.40$. The airfoil exhibits a rapid, trailing-edge 
stall, which does not meet the design goal of docile stall characteristics. Low profile-drag coefficients are exhibited over the range of lift coefficients from 0.05 to 1.10. The lower limit of the low-drag range is below the design objective of $c_{l, 11}=0.40$ although the upper limit is also below the design objective of $\mathrm{c}_{l, \mathrm{ul}}=1.20$, primarily to meet other, more important goals. The drag coefficient at $\mathrm{c}_{l}=0.40$ is 0.0068 , which satisfies the design objective of $c_{d, \text { min }} \leq 0.0080$. The zero-lift pitching-moment coefficient is -0.15 , which satisfies the design constraint of $\mathrm{c}_{\mathrm{m}, 0} \geq-0.15$.

Comparisons of the predicted and measured section characteristics generally show the magnitudes of the zero-lift angle, the pitching moment coefficient, and the width of the low-drag range are overpredicted. The maximum lift coefficient is underpredicted.

\section{Section Characteristics of S827 Airfoil}

The theoretical and experimental section characteristics of the S827 airfoil for the design Reynolds number of 4 $\times 10^{6}$ are shown in Fig. 6 . The measured maximum lift coefficient is 1.28 , which substantially exceeds the design objective of $\mathrm{c}_{l, \text { max }} \cong 1.00$. Low profile-drag coefficients are exhibited over the range of lift coefficients from 0.04 to 0.75 . The lower limit of the low-drag range is below the design objective of $\mathrm{c}_{l, 11}=$ 0.20 although the upper limit is also below the design objective of $\mathrm{c}_{l, \mathrm{ul}}=0.80$, primarily to meet other, more important goals. The drag coefficient at $\mathrm{c}_{l}=0.20$ is 0.0049 , which satisfies the design objective of $\mathrm{c}_{\mathrm{d} \text {,min }} \leq$ 0.008 . The zero-lift pitching-moment coefficient is 0.07 , which satisfies the design constraint of $\mathrm{c}_{\mathrm{m}, 0} \geq-$ 0.07 .

Comparison of predicted and measured section characteristics generally shows the magnitudes of the zero-lift angle and the pitching moment coefficient are overpredicted. The width of the low-drag range is also overpredicted. The maximum lift coefficient is significantly underpredicted with increasing Reynolds number.

\section{Effect of Roughness}

The effect of fixing transition on the section characteristics is shown in Figs. 7 and 8 for the S825 and S827 airfoils, respectively. In general, the liftcurve slope, the maximum lift coefficient, and the magnitudes of the zero-lift angle of attack and the pitching-moment coefficients decrease with transition fixed. These results are primarily a consequence of the boundary-layer displacement effect, which decambers the airfoil, the displacement thickness being greater with transition fixed than with transition free. In addition, the lift-curve slope and the maximum lift coefficient decrease with transition fixed because the roughness induces early trailing-edge separation, particularly at high angles of attack. Both airfoils exhibit no hysteresis for angles of attack beyond stall. The maximum lift coefficient of the S825 airfoil for the design Reynolds number of $2 \times 10^{6}$ is 1.52 , a reduction of less than 3 percent from that with transition free. The maximum lift coefficient of the S827 airfoil for the design Reynolds number of $4 \times 10^{6}$ is 1.26 , a reduction of less than 2 percent from that with transition free. The drag coefficients are, of course, adversely affected by the roughness.

The effect of the scaled, NACA standard roughness on the section characteristics is more severe than that of fixing transition. The maximum lift coefficient of the S825 airfoil for the design Reynolds number of $2.0 \times$ $10^{6}$ is 1.34 , a reduction of 14 percent from that with transition free. The maximum lift coefficient of the S827 airfoil for the design Reynolds number of $4 \times 10^{6}$ is 1.06 , a reduction of 17 percent from that with transition free. The greater reduction of 17 percent for the S827 airfoil versus 14 percent for the S825 may be attributed to two effects. First, roughness losses have been found to be proportional to airfoil thickness ${ }^{12}$. Second, the effect of roughness is proportional to the ratio of the roughness height to the boundary-layer thickness. Because the roughness height of the scaled, NACA standard roughness and the airfoil chord are constant, the effect of this roughness generally increases with increasing Reynolds number (because the boundary-layer thickness decreases with increasing Reynolds number).

\section{Reynolds Number Effects}

The variation of maximum lift coefficient with Reynolds number for the S825 and S827 airfoils is shown in Figs. 9 and 10, respectively. The maximum lift coefficient increases with increasing Reynolds number. The rate of increase is similar with transition free and transition fixed but lower with the scaled, NACA standard roughness.

The variation of profile-drag coefficient with Reynolds number is shown in Fig. 11 and Fig. 12 for the S825 and S827, respectively. For both airfoils the drag coefficient generally decreases with increasing Reynolds number, except at a Reynolds number of $1 \times$ $10^{6}$, when bubble drag is decreased from early boundary layer transition. 


\section{Conclusions}

Comparisons of the theoretical and experimental airfoil section characteristics illustrate weaknesses in the theoretical methodology. The most significant discrepancy is in the prediction of the maximum lift coefficient, which is substantially underpredicted by the Eppler code for both the low and high lift airfoils. This discrepancy becomes larger with increasing Reynolds number. Another discrepancy was the prediction of a wider drag bucket relative to measurements.

For the high-lift S825 airfoil, the measured maximum lift coefficient is somewhat higher than the predicted value. The airfoil exhibits a rapid, trailing-edge stall, rather than the goal of docile stall characteristics. The measured minimum drag and pitching moment coefficient agreed favorably with predictions.

For the low-lift S827 airfoil, the measured maximum lift coefficient is substantially higher than the predicted value. This comparison emphasizes the difficulty of designing a low-lift airfoil for high Reynolds numbers. The measured minimum drag and pitching moment coefficient agreed favorably with predictions.

\section{References}

${ }^{1}$ Eppler, R., 1998, "Airfoil Program System

“PROFIL98.” User's Guide,” c. 1998.

${ }^{2}$ Von Doenhoff, A. E., and Abbott, F. T., Jr., "The Langley Two-Dimensional Low-Turbulence Pressure Tunnel,” NACA TN 1283, 1947.

${ }^{3}$ McGhee, R. J., et al., "Recent Modifications and Calibration of the Langley Low-Turbulence Pressure Tunnel,"NASA TP-2328, 1984.
${ }^{4}$ Tangler, J. L., and Somers, D. M., "NREL Airfoil Families for HAWTs," American Wind Energy Association WindPower '95, Washington, DC 1995.

${ }^{5}$ Somers, D. M., "Design and Experimental Results for the S825 Airfoil," NREL Report to be published 1999.

${ }^{6}$ Somers, D. M., "Design and Experimental Results for the S827 Airfoil," NREL Report to be published 1999.

${ }^{7}$ Wlezien, R. W., et al., "Comparison of Flow Quality in Subsonic Pressure

Tunnels," AIAA Paper 94-2503, 1994.

${ }^{8}$ Allen, H. J., and Vincenti, W. G., "Wall Interference in a Two-Dimensional-Flow Wind Tunnel, With Consideration of the Effect of Compressibility," NACA Rep. 782, 1944.

${ }^{9}$ Pankhurst, R. C., and Holder, D. W., "Wind-Tunnel Technique," Sir Isaac Pitman \& Sons, Ltd. (London), 1965.

${ }^{10}$ Abbott, I. H., Von Doenhoff, A. E., and Stivers, L. S., Jr., "Summary of Airfoil Data," NACA Rep. 824, 1945.

${ }^{11}$ Braslow, A. L. and Knox, E. C., "Simplified Method for Determination of Critical Height of Distributed Roughness Particles for Boundary-Layer Transition at Mach Numbers From 0 to 5," NACA TN 4363, 1958.

${ }^{12}$ Tangler, J. L., and Somers, D. M., "Effect of Airfoil Thickness and Maximum Lift on Roughness Sensitivity," $3^{\text {rd }}$ ASME JSME Joint Fluids Engineering Conference, San Francisco, CA, 1999. 
Table 1. Airfoil Design Specifications.

\begin{tabular}{|l|c|c|}
\hline \multicolumn{1}{|c|}{ Airfoil } & $\mathrm{S} 825$ & $\mathrm{~S} 827$ \\
\hline \multicolumn{1}{|c|}{ Parameter } & \multicolumn{2}{c|}{ Objective/Constraint } \\
\hline Reynolds number $\mathrm{R}$ & $2 \times 10^{6}$ & $4 \times 10^{6}$ \\
\hline Maximum lift coefficient $\mathrm{c}_{l, \text { max }}$ & $\geq 1.40$ & $\cong 1.00$ \\
\hline Lower limit of low drag, lift coefficient range $\mathrm{c}_{l, 11}$ & 0.40 & 0.20 \\
\hline Upper limit of low-drag, lift coefficient range $\mathrm{c}_{l, \mathrm{ul}}$ & 1.20 & 0.80 \\
\hline Minimum profile-drag coefficient $\mathrm{c}_{\mathrm{d}, \min }$ & $\leq 0.0080$ & $\leq 0.0080$ \\
\hline Zero-lift pitching-moment coefficient $\mathrm{c}_{\mathrm{m}, 0}$ & $\geq-0.15$ & $\geq-0.07$ \\
\hline Airfoil thickness t/c & $17 \%$ & $21 \%$ \\
\hline
\end{tabular}
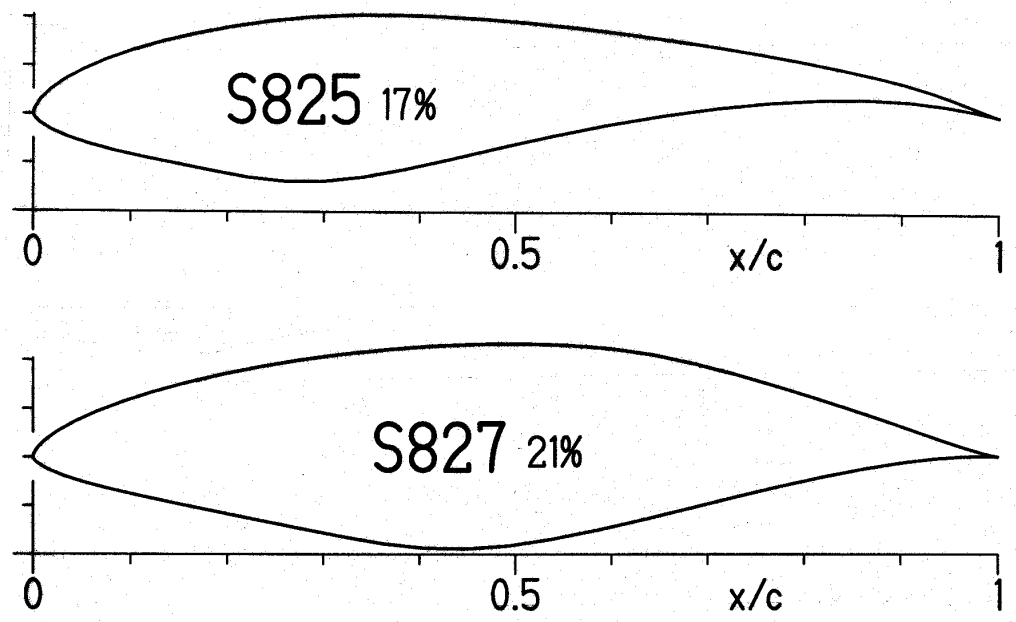

Fig. 1. S825 and S827 airfoil shapes.

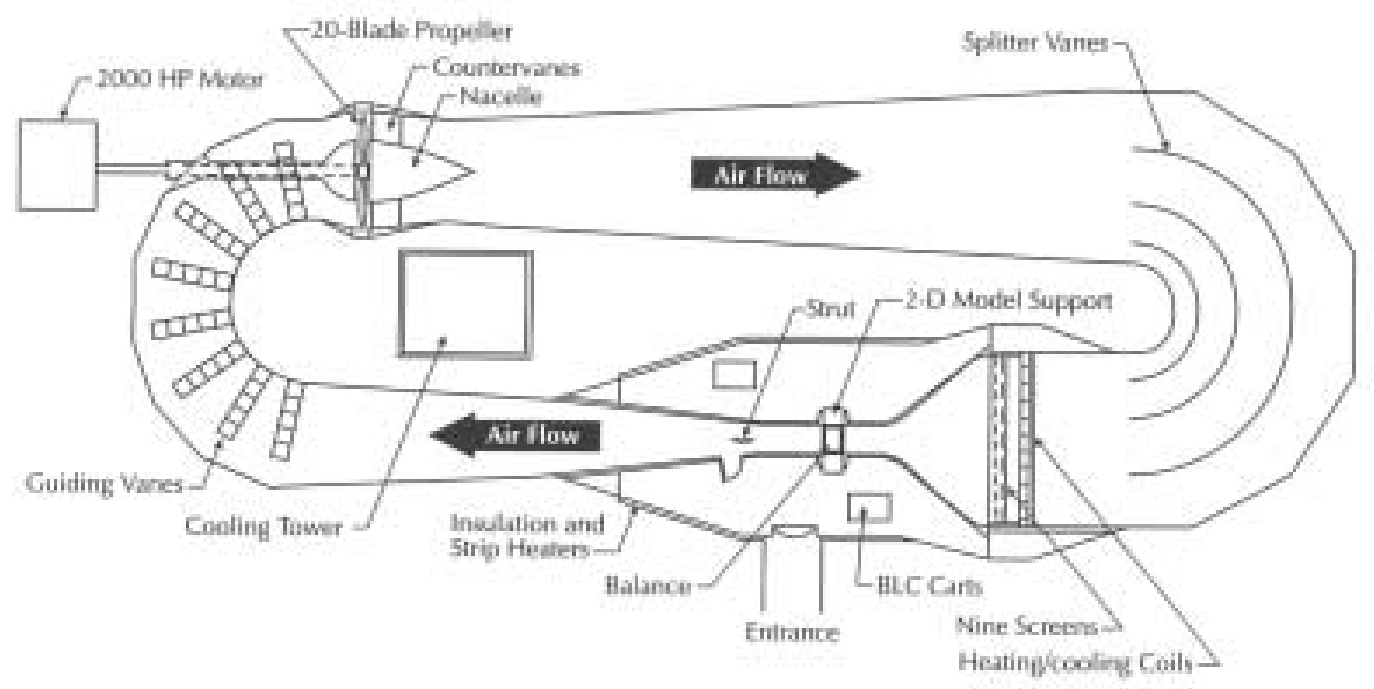

Fig 2. The NASA Langley Low Turbulence Pressure Tunnel.

Table 2. Roughness Location and Size. 


\begin{tabular}{|c|c|c|c|c|}
\hline \multirow{2}{*}{$\begin{array}{l}\text { Reynolds } \\
\text { Number }\end{array}$} & \multicolumn{2}{|r|}{ Upper Surface } & \multicolumn{2}{|r|}{ Lower Surface } \\
\hline & $\mathrm{x} / \mathrm{c}$ & Grit Number/Size & $\mathrm{x} / \mathrm{c}$ & Grit Number/Size \\
\hline $1.0 \times 10^{6}$ & \multirow[t]{5}{*}{0.02} & $\begin{array}{l}90 / 0.178 \mathrm{~mm} \text { (0.0070in.) } \\
\end{array}$ & \multirow[t]{5}{*}{0.05} & 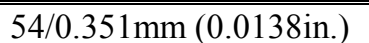 \\
\hline $2.0 \times 10^{6}$ & & $180 / 0.089 \mathrm{~mm}$ (0.0035in.) & & $80 / 0.211 \mathrm{~mm}(0.0083 \mathrm{in})$. \\
\hline $3.0 \times 10^{6}$ & & \multirow{3}{*}{ 220/0.074mm (0.0029in.) } & & $100 / 0.150 \mathrm{~mm}$ (0.0059in.) \\
\hline $4.0 \times 10^{6}$ & & & & \\
\hline $6.0 \times 10^{6}$ & & & & $180 / 0.089 \mathrm{~mm}(0.0035 \mathrm{in})$. \\
\hline
\end{tabular}

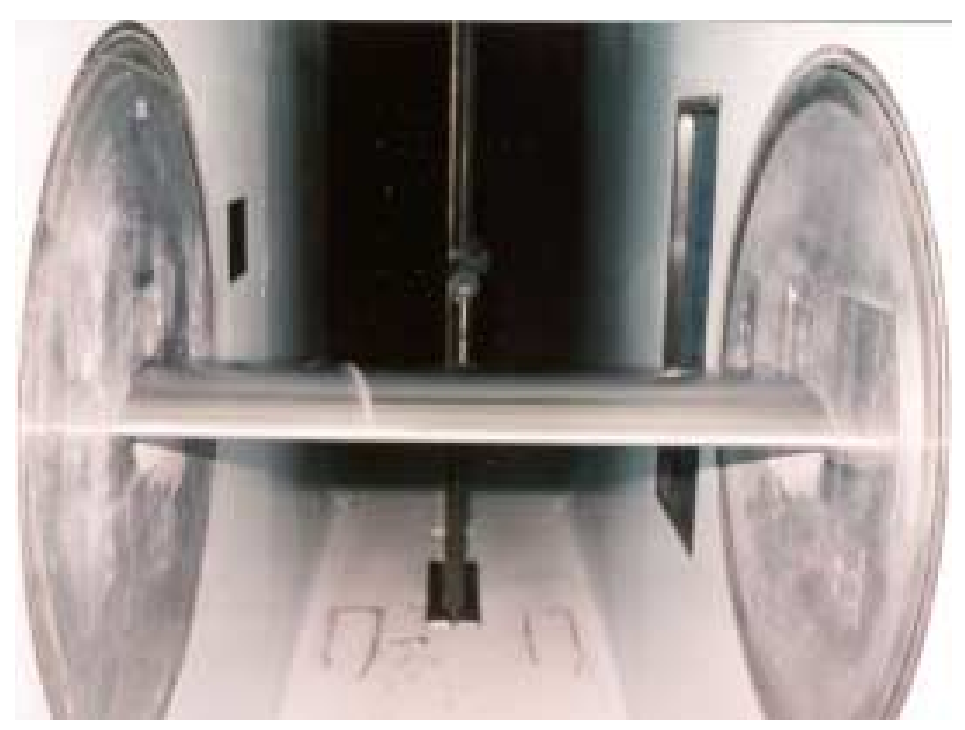

Fig. 3. LTPT test section.
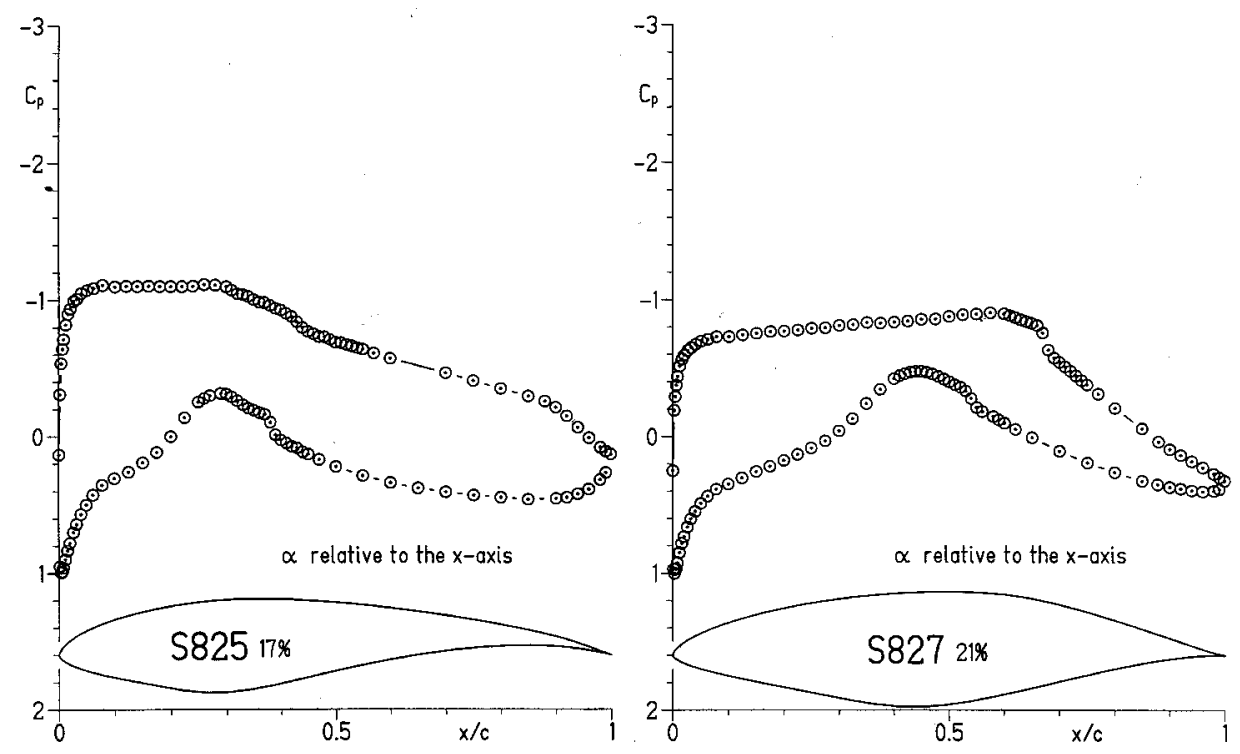

Fig. 4. Typical pressure distributions $\left(\alpha=3.0^{\circ}\right)$. 


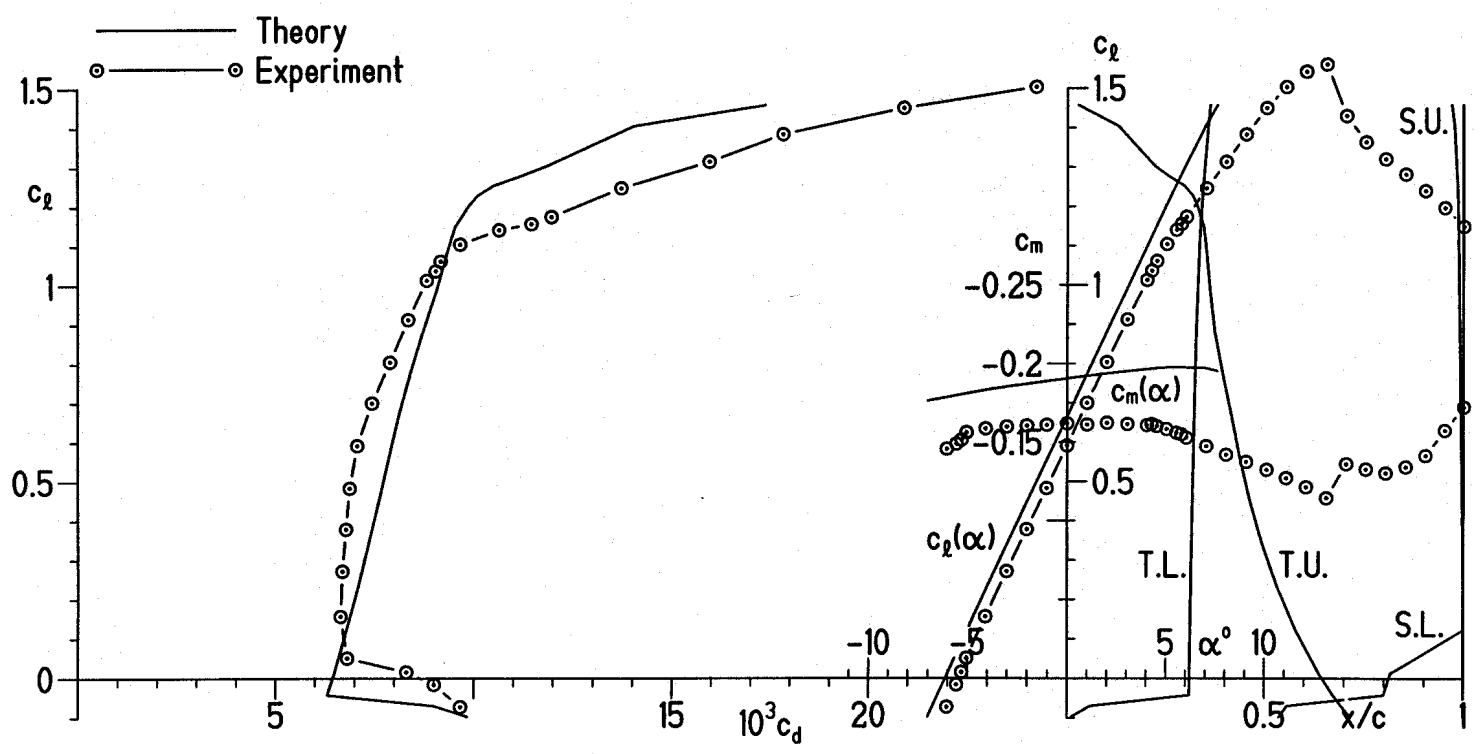

Fig. 5. Comparison of theoretical and experimental section characteristics of S825 airfoil with transition free for design Reynolds number of $2 \times 10^{6}$.

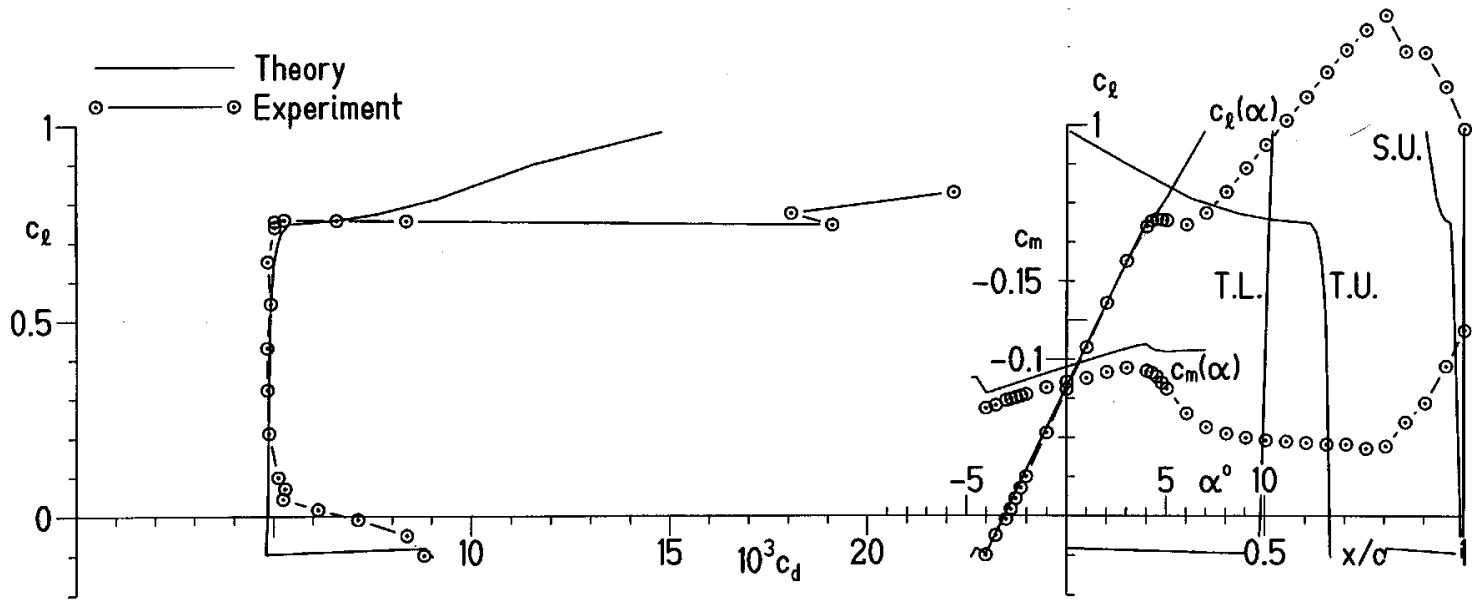

Fig. 6. Comparison of theoretical and experimental section characteristics of S827 airfoil with transition free for design Reynolds number of $4 \times 10^{6}$. 


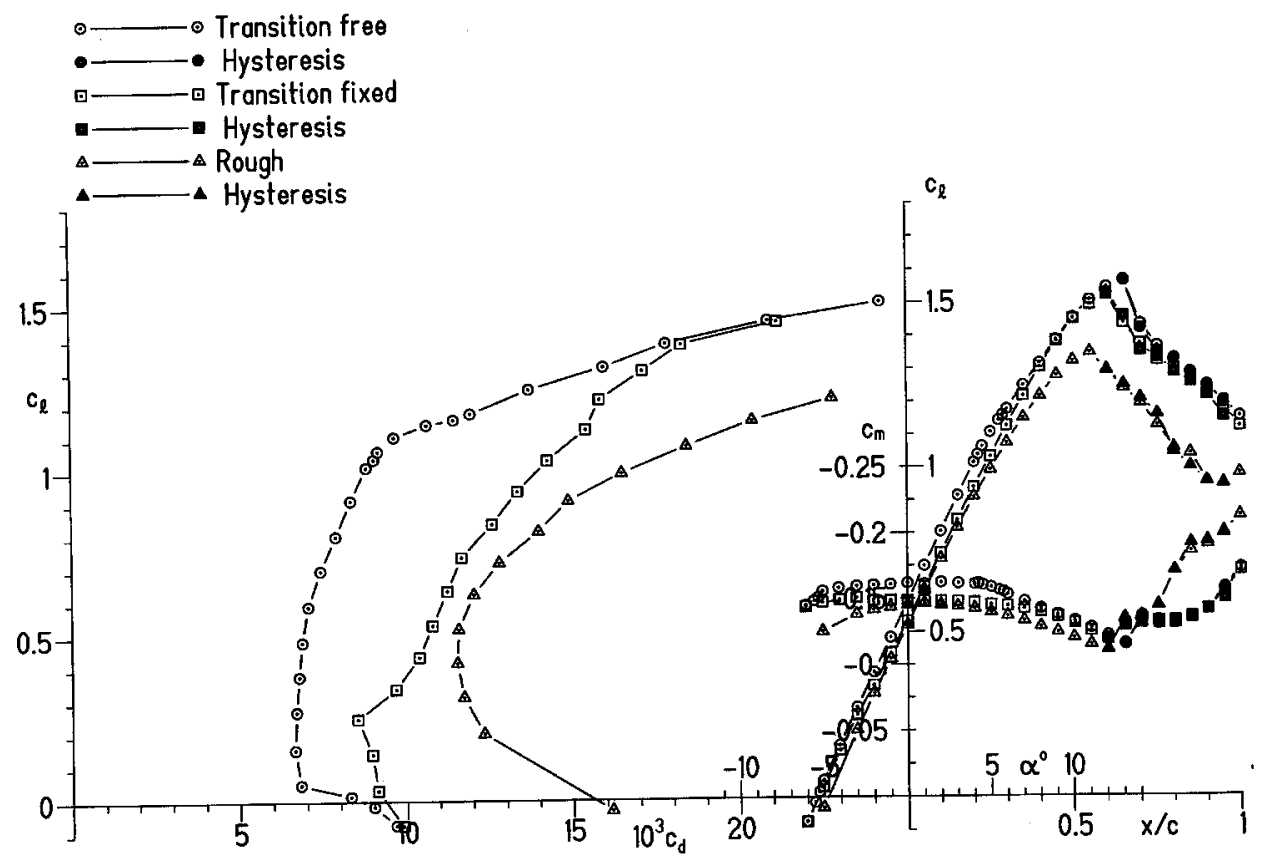

Fig. 7. Section characteristics of S825 airfoil with transition free, transition fixed, and scaled, NACA standard roughness for design Reynolds number of $2 \times 10^{6}$.

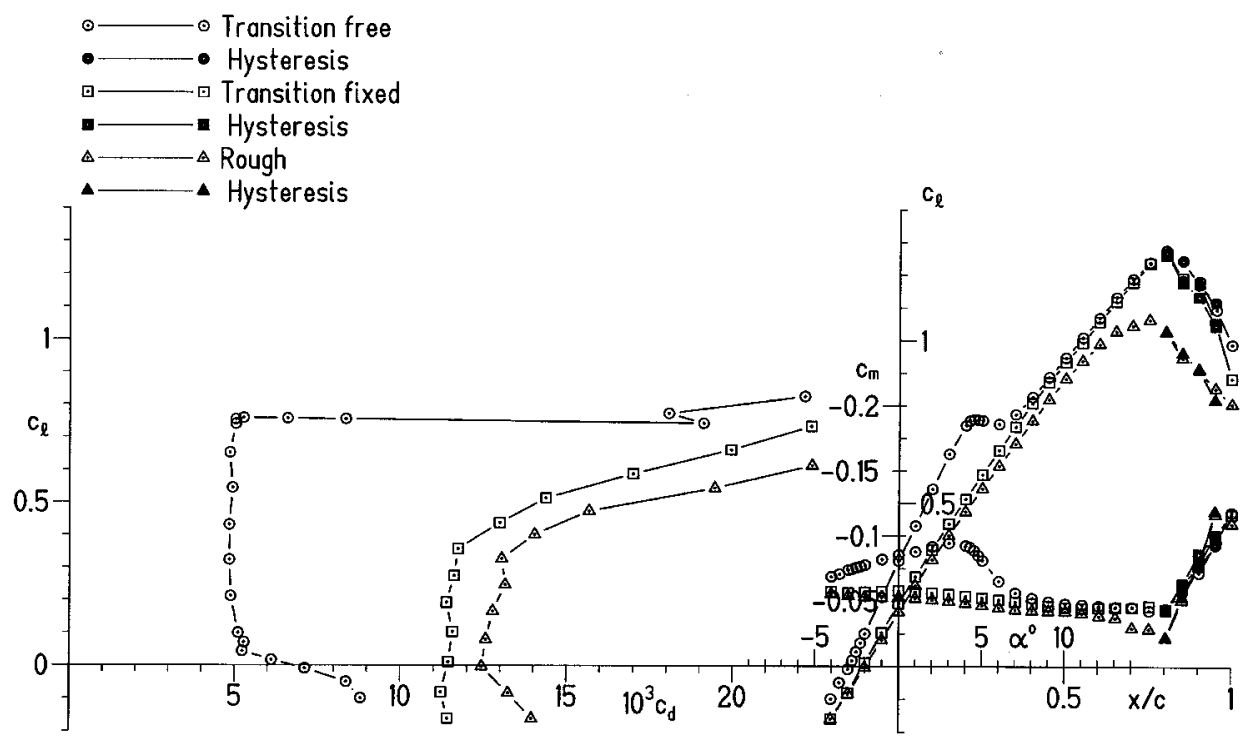

Fig. 8. Section characteristics of S827 airfoil with transition free, transition fixed, and scaled, NACA standard roughness for design Reynolds number of $4 \times 10^{6}$. 


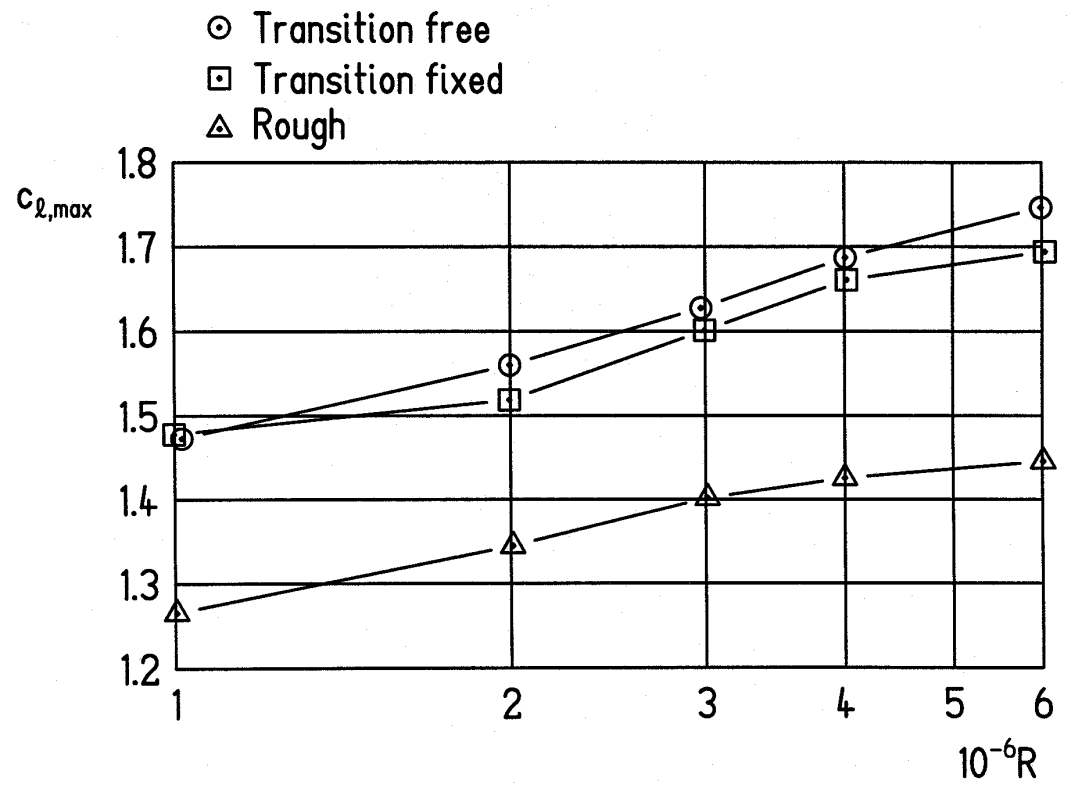

Fig. 9. Variation of maximum lift coefficient with Reynolds number for S825 airfoil.

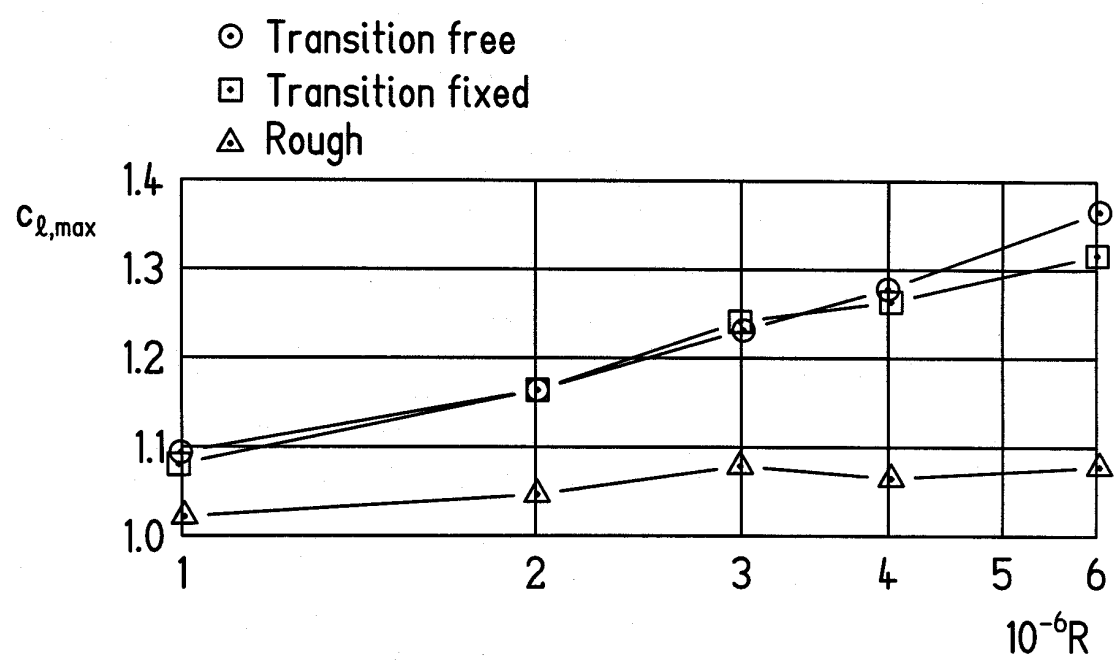

Fig. 10. Variation of maximum lift coefficient with Reynolds number for S827 airfoil. 


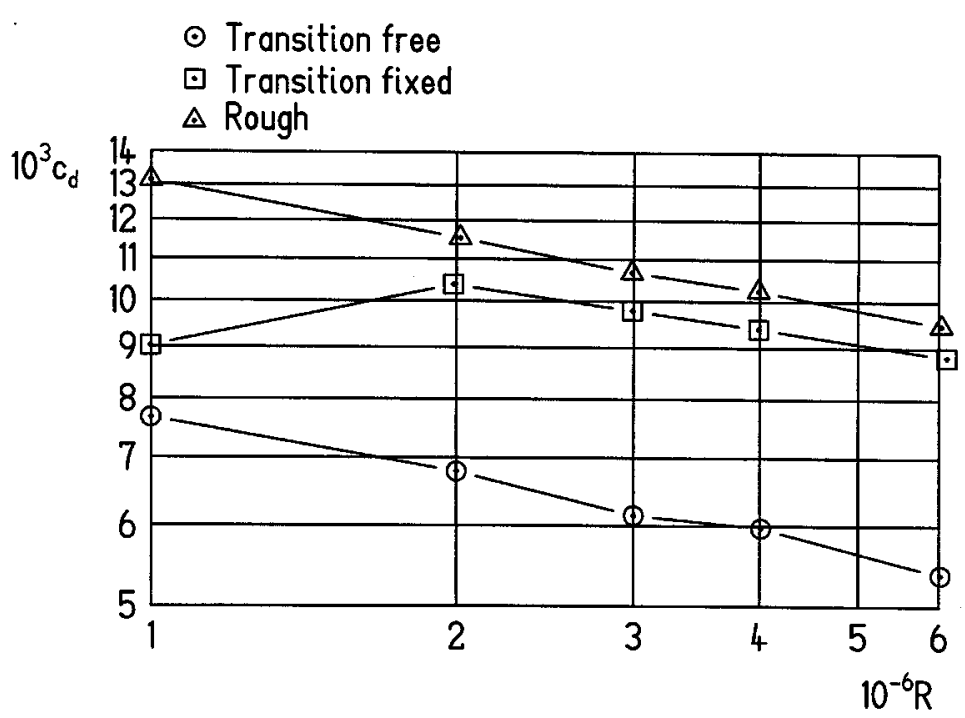

Fig. 11. Variation of profile-drag coefficient at $\mathrm{c}_{l}=0.4$ with Reynolds number for $\mathrm{S} 825$ airfoil.

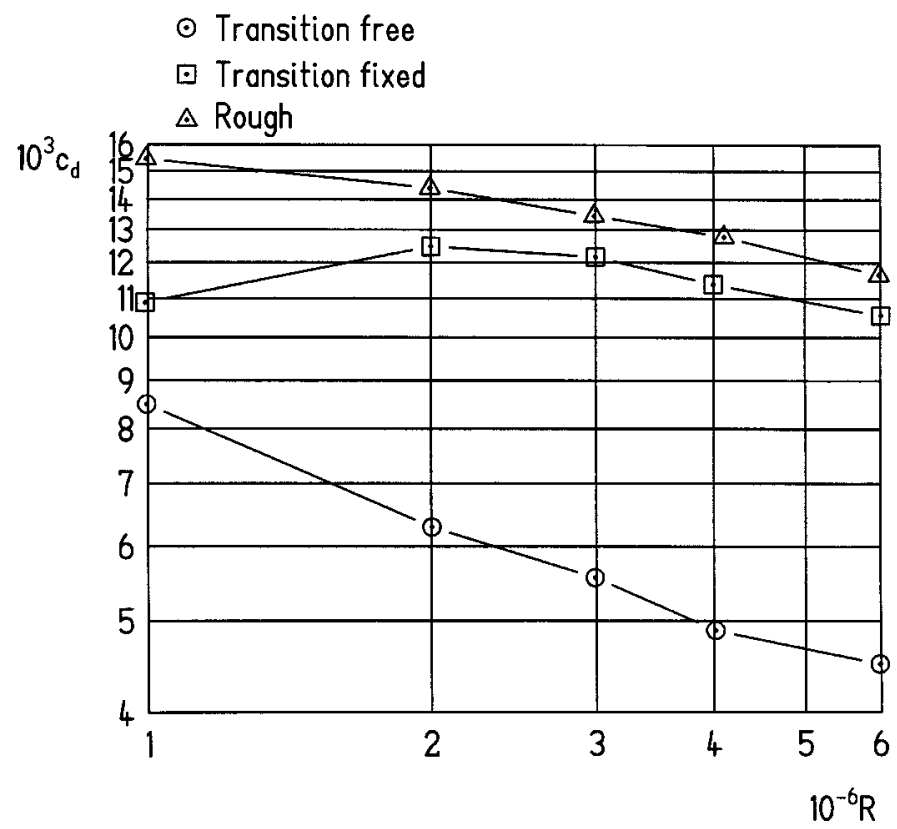

Fig. 12. Variation of profile-drag coefficient at $\mathrm{c}_{l}=0.2$ with Reynolds number for $\mathrm{S} 827$ airfoil. 